\title{
Human resource development in the implementation of the concept of "smart cities"
}

\author{
Elena Avdeeva ${ }^{1, *}$, Tatyana Davydova ${ }^{1}$, Nadezhda Skripnikova $^{1}$, Larisa Kochetova $^{2}$ \\ ${ }^{1}$ Voronezh State Technical University, Moscovskiy prospect, 14, Voronezh, 394026, Russia \\ ${ }^{2}$ Russian University of Justice (Central branch), 20-letya Oktyabrya 95, Voronezh, 394006, Russia
}

\begin{abstract}
The improvement of urban systems based on the active use of information technologies, which is necessary to achieve these goals, requires specialists with appropriate qualifications. This article uses a methodological approach to the study of human resource development from the perspective of two-way communication between producers and consumers of an innovative product. The educational, structural-industry and information technology aspects of development are considered. The results of the analysis are presented, and the methods of partnership cooperation between higher educational institutions and representatives of the business community in the construction and housing and utilities sectors are identified. The experience in the field of training and retraining specialists in construction specialties with elements of student research has been synthesized. The prospects for improving the system of personnel training in the field of housing and communal services are identified. A SWOT analysis of the strengths and weaknesses of urban modernization has been carried out. Among the weaknesses, the failure of highly qualified specialists was revealed. Among the threats is the absence of a legislative and methodological framework in many areas of housing and communal services reforming. In the annex to the concept of "smart cities", Rohmer's model is considered, confirming the primary role of human resources in reforming and further operating the urban infrastructure. It is shown that the success of the initiative of a smart city depends on personnel, processes and technologies.
\end{abstract}

\section{Introduction}

The role of cities in the global economy is significant, and it is constantly increasing. With increasing population, energy consumption and other global resources are growing.

With this in mind, according to researchers, the optimization of the functioning of urban structures [1-4] is becoming increasingly important. The "Smart City" project was launched in Russia in 2018 in a pilot mode, and from 2019 it became mandatory within two national projects at once - "Housing and urban environment" and "Digital economy". In addition, the creation and implementation of the concept of "smart cities" on the territory of the Russian Federation was the goal of forming a National Consortium for the development and

\footnotetext{
*Corresponding author: avdeeva_ea@mail.ru
} 
implementation of digital technologies in the field of urban management. At the same time, the professional self-realization of the specialists of the relevant field is stated as the main task of the consortium. This circumstance is due to the fact that the increasingly effective, focused on raising the level and living standards, the development of economic activity is associated with the digital economy $[1,5,7]$. Accordingly, modern intellectual production requires from specialists the ability to set and solve the problems of designing innovative products and services, innovative production, marketing and use of modern information and communication technologies. The successful implementation of the concept of "smart cities" is directly dependent on the development of human potential in general and, to the greatest extent, on the development of human resources potential $[6,7,8]$.

Intellectual production requires intellectual consumption. Therefore, we suppose that the development of human resources is methodologically expedient to consider from the position of a bilateral approach. Each producer of innovative goods and services is simultaneously a consumer of an equally innovative product. Consequently, the options of significant interrelations and interdependencies considered by us in this study and displayed in Figure 1 come to the fore.

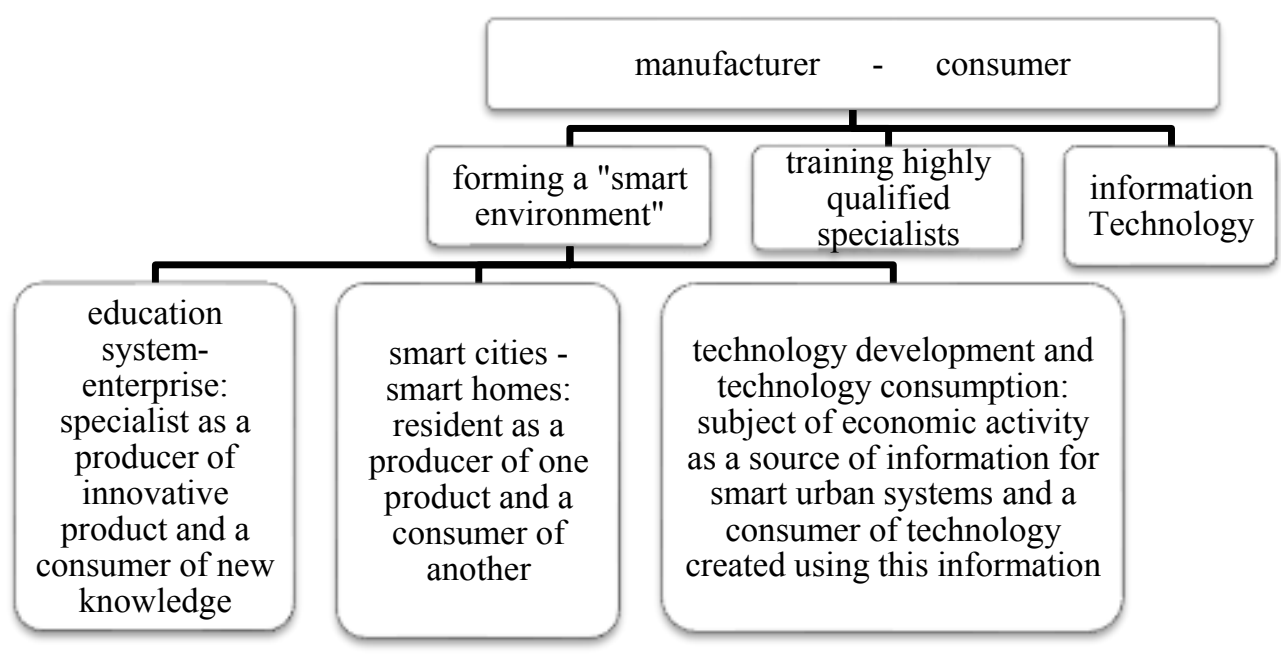

Fig. 1. The duality nature of the category of personnel potential.

First, education is production, in the form of a partnership of educational institutions, government authorities and business representatives in the training of personnel to ensure the functioning of the "smart city" and its structural components [9-13]. Secondly, a smart city is a smart home, involving the active participation of both producers and consumers of housing and communal services in the development of "smart" technologies $[7,12,14,15]$. Thirdly, information technology is an effective activity, as an option, necessitating both the development and use of a technological product, and the increase of the level of knowledge and skills in the field of information technology by specialists in all areas and types of modern activities $[1,5,16]$.

It is important to note that the relationships described in Figure 1 are not isolated from each other, their boundaries are not strictly defined. Since individual business entities at different times and under different conditions are related to each specified option, an integrated approach gives the best result. 
Thus, the research objective is to identify methods for the development of personnel potential in relation to the concept of "smart cities" from the position of the noted variants of interconnections.

\section{Materials and Methods}

Our analysis of employer survey data showed that the best results are found when organizing a partnership of educational institutions and enterprises, initiated by representatives of the business community $[9,10]$. This is due to the existing contradiction. For a large number of potential employers, cooperation with an educational institution has minimal importance, and personal interaction with a graduate in the process of his training has an essential importance. As a result, in a number of cases, employers are initially oriented towards training graduates with the necessary competences in the process of adaptation to work and at the beginning of work, or are forced to act in a similar way.

In the course of the research, the authors found that the effective development of cooperation between enterprises and universities in the system of training specialists with in-demand competencies can be carried out using the following methods.

The first is a synthesis method based on the creation of global integrated structures in the field of personnel training by educational organizations of higher education in cooperation with enterprises. Research and educational centers based on business incubators, research and educational complexes consisting of an enterprise or a research institute, a basic department and an educational organization can act as such structures. As an example of using this method in world practice, one can cite the experience of the University of Arkansas in training specialists in the field of energy audit [12]. The disadvantage of this method is the substantial financial and administrative costs of creating such centers and complexes.

The second method is learning from the general to the particular, according to an individual plan. In the undergraduate courses, students receive basic theoretical knowledge together, and in the senior courses, they are taught individually, in order to ensure the possibility of combining training with direct official duties in the organization. For example, partners of the Voronezh State Technical University (VSTU) are introducing additional specializations; the use of the material base of the organization for training, educational and industrial practices; joint assessment of the professional competencies of students with employers. The disadvantage of the method is a strict orientation on a specific type of activity without taking into account the dynamics of the labor market and the preferences of the future specialist.

The first two methods are directly related to the variant of interaction education production. The following methods are applicable to all options for interaction between stakeholders of the "smart city".

The third method is modeling the employer's requirements for employees of the enterprise. It is intended to retrain personnel, improve the skills of workers at the initiative of the enterprise. The basis for the implementation of the noted activities can be both a workplace and a university. On the basis of VSTU, an additional vocational education department was organized, which provides training in 26 advanced training and professional retraining programs. The educational programs include the Safety of construction and the quality of the installation of electrical networks and communication lines; Construction safety, organization of construction, reconstruction and major repairs; Safety of construction and quality of performance of facade works, roofing, protection of building structures, pipelines and equipment, including at technically complex, especially dangerous objects. 
The disadvantage of the method is the weak interest of the employer in cooperation with universities. As a rule, advanced training is carried out on the job.

The fourth method - from the particular to the general, increasing the level of literacy of the population as a whole in various fields of human activity. It assumes free access to knowledge for any citizen. An example is the Housing and Public Utilities Center "People's Institute", organized on the basis of the VSTU. The disadvantage of the method is substantial financial costs.

The fifth method is targeting. In accordance with the special relevance, various aspects of the transfer knowledge and skills demanded in the existing conditions are being worked out. This applies primarily to information technology. On the basis of VSTU, an Autodesk Authorized Training and Certification Center, the Center for Educational Computer Technologies, and the Design Center for Digital Territories are operating. It is practiced both training and advanced training of specialists in various fields, obtaining additional competences by them. The disadvantage of the method is the substantial financial costs for consumers of educational services and their weak interest.

Finally, the sixth method is scientific and practical. Here we include the organization of scientific and practical events that facilitate the organization of communication interaction between stakeholders. In particular, we can talk about the All-Russian Forum «BIM. Design. Building. Operation» held annually on the basis of VSTU with the participation of partners - developers of engineering software, design organizations, IT companies, including Schneider Electric, a global expert in energy management and industrial automation, Autodesk CIS is a developer of automated 2D and 3D design and others. Target audience - regional authorities, universities and educational organizations of secondary vocational education, business participants, investors, professors and staff of universities, students. The forum includes the presentation of business projects, thematic lectures, the organization of round tables, panel discussions and master classes, competitions, including student ones [8]. The disadvantage is the poor awareness of potential participants of the events.

\section{Results}

The main reasons for the digitization of urban infrastructure are technological, economic and environmental changes, including the large-scale distribution of the Internet, the transition to online retail and entertainment, changes in the structure of the economy, urban population growth and strong pressure on public finances. Infrastructure is commonly understood as the totality of industries and activities that serve the production and nonproduction sectors of the economy in order to create conditions for the normal activities of the main industries or the basic enterprise of material production. The development of infrastructure and its functions has led to the separation of engineering, environmental and social. Sectors that improve "smart city" technology include the rationalization of public services, the management of urban transport networks, health care, the rational use of energy, water, innovative agriculture and waste management. Digitalization will cover almost all spheres of city activity: economy, finance, management, infrastructure, residents, environment, technology.

In the process of research, we conducted a SWOT analysis of the modernization of the urban environment, the results are presented in Table 1. Obviously, the modernization of the economy is connected not so much with the newest equipment and technologies, but with the new thinking, human needs and attitudes that must be studied and formed on the basis of the traditions of Russian science, both technical and socio-humanitarian. The Smart City infrastructure specialist is an expert, whose activity is aimed at introducing 
information technologies and Internet of Things (IoT) objects into the urban environment, thereby ensuring improvement of the management system and interaction of the state with the society, improving quality and efficiency work of urban services, as well as the life quality of citizens in general.

Table 1. SWOT-analysis of urban modernization.

\begin{tabular}{|l|l|}
\hline Strengths & Weaknesses \\
\hline $\begin{array}{l}\text { Improving the standard of living of citizens } \\
\text { and reducing the costs of business processes } \\
\text { through automation }\end{array}$ & $\begin{array}{l}\text { Not enough qualified specialists } \\
\text { lack of necessary capacity }\end{array}$ \\
$\begin{array}{l}\text { continuous processing and updating of } \\
\text { information thanks to integrated sensors in } \\
\text { all areas of the urban economy }\end{array}$ & $\begin{array}{l}\text { lhe development of smart cities requires } \\
\text { considerable costs and the use of modern } \\
\text { equipment, and to store big data you need the } \\
\text { latest servers }\end{array}$ \\
$\begin{array}{l}\text { feedback between the administration and } \\
\text { citizens, improvement of the environment }\end{array}$ & $\begin{array}{l}\text { information is collected by too heterogeneous } \\
\text { devices - navigators, smartphones, search } \\
\text { engines, i.e. there is no single system for } \\
\text { collecting and analyzing data }\end{array}$ \\
$\begin{array}{l}\text { creating an enabling environment for } \\
\text { innovation }\end{array}$ & $\begin{array}{l}\text { Threats } \\
\text { Opportunities }\end{array}$ \\
\hline $\begin{array}{l}\text { Optimization solving the problems of urban } \\
\text { inefficiency } \\
\text { methodological base in many areas of } \\
\text { reforming housing and communal services } \\
\text { and for creating unified scientific and } \\
\text { educational complexes in the production } \\
\text { system }\end{array}$ \\
$\begin{array}{l}\text { Megacities bring a significant income in the } \\
\text { development of the IT industry, the cost of } \\
\text { which in a couple of years will be } \\
\text { approximately 1.5 trillion. dollars }\end{array}$ \\
$\begin{array}{l}\text { The concept of a "smart city" is the main tool } \\
\text { for managing megacities }\end{array}$ \\
$\begin{array}{l}\text { The huge cost of projects, and most of it falls } \\
\text { on consumers (paying for paid parking, video } \\
\text { surveillance, installing smart gas, light, water } \\
\text { meters, etc.) - this can lead to the } \\
\text { public transport }\end{array}$ \\
$\begin{array}{l}\text { Development of domestic and foreign } \\
\text { tourism }\end{array}$ \\
$\begin{array}{l}\text { Make life easier and safer, better and more } \\
\text { comfortable }\end{array}$ & $\begin{array}{l}\text { Imperfection, not debugged work of Internet } \\
\text { services (do not work, hang, load data for a } \\
\text { long time, do not pass payment, etc.). }\end{array}$ \\
\hline
\end{tabular}

The problem of training and retraining workers and managers for housing and communal services today is becoming increasingly important for the economy of the country. The solution of the personnel problem will determine how effectively billions will be spent on housing and communal services reforming. According to a study by the Academy of Public Utilities and Construction, the share of housing and public utilities workers with higher specialized professional education by 2012 was only $7 \%$. The lack of professional personnel in this industry exceeded $47 \%$. At the same time, more than 2 million people work in the housing and utilities sector. A large number of people in the industry is a sign of outdated technology and low productivity. One of the reasons for the lack of qualified personnel in housing and communal services is the lack of vocational education systems and systematic work with young people. This includes a system of state order for training, methodological support of this work, professional standards, a mechanism for personalizing responsibility, lack of certification and accreditation of staff. 
As a result, the average age of workers in the industry is close to 50 years. It is easy to assume that in ten years, there will be no one to work.

There is another serious problem - the prestige of the profession, the prestige of workers in the housing and communal sector. Since Soviet times, the notion that workers in the housing and utilities sector are losers, drinkers, limiters, and now migrant workers has taken root in people's minds.

According to one of the specialists, the formation of higher educational institutions, combining primary, secondary and higher vocational education on the basis of the dual form of education in their structure, which will lead to an increase in the quality of educational services in training for housing and public utilities, can also be a way out of the personnel impasse.

Currently, applicants will be able to choose for themselves another new specialty in the housing and utilities sector - "Master in repair and maintenance of engineering systems for housing and utilities", and upon graduation, graduates will be awarded qualifications as a plumber and electrician in lighting and lighting networks. Today, there is a great demand for this profession, with a high level of wages for such specialists.

Since 2016, in some higher education institutions of the Russian Federation, students receive a secondary vocational education in the specialty "Management, operation and maintenance of an apartment building", which includes works on the operation, maintenance and repair of the general property of the apartment buildings, as well as the organization of payments for housing and communal services. Currently, the list of educational institutions where you can learn this profession continues to expand. Also within the "Service" direction, it is possible to study on a full-time basis on the profile "Service and Management of Real Estate and Commercial Infrastructure". Among the most popular professions is the design of the urban environment.

Yevgeny Bogomolny, Chairman of the Commission for Facilitating the Training of Housing and Public Utilities Personnel of the Supervisory Board of the Housing and Utilities Fund, Professor of the Russian Academy of National Economy and Public Administration under the President of the Russian Federation Housing and Public Utilities, will be able to get a bachelor and master degree from colleges and technical schools today "Housing and communal infrastructure" on a budget and contract basis. Increased knowledge in the field of housing and communal services is also available to owners, chairmen of houses and homeowners. The magistracy in the direction of preparation "Housing and Communal Infrastructure" was opened [17].

Today, the housing and utilities professions have already been entered in the register of the Ministry of Science and Higher Education of the Russian Federation, and a plan for training personnel in the housing and utilities sector has been approved by a decree of the Russian Government.

Personnel training in the housing and utilities sector is a priority for resource supply and management companies. In this academic year, the training of specialists for the housing and utilities sector on the basis of new federal state educational standards began in the educational institutions of the country.

\section{Discussions}

The urgency of the task of creating "smart cities" is growing, and an increasing number of researchers are involved in the discussion of various aspects of the concept. At the same time, there is an opinion that it is necessary to develop the personnel potential to successfully accomplish the task. The task is complicated by the fact that the consumption of an innovative product created by a highly qualified specialist also requires special knowledge and skills from the consumer. Thus, if we consider each person from the 
standpoint of the simultaneous production and consumption of various goods and services created and used in the information economy, the importance of education of all stakeholders comes to the fore.

The interaction of enterprises and educational institutions allows the process of development of human resources at all stages of the specialist and most fully. Equally important and much more cooperation is needed between the public and private sectors in order to find more effective solutions to improve the lives of citizens.

Rapid urbanization means investing in the future. We can no longer rely on decisions that we consider correct, we need to use data collected by experts to make sure that decisions made in the city are based on facts and known patterns.

Modernization of general and vocational education, including through the introduction of adaptive, practice-oriented and flexible (modular) educational programs is necessary.

Consider the Romer's model - a model of endogenous scientific and technological progress, based on the idea of accumulating human capital. He compared the development of the economy with the centralized management of investment in research and market competitive investments.

The most important factors are technological changes that occur due to the targeted activity of people - the further use of the created technologies does not require additional costs from the manufacturer. P. Romer divided the economy into three sectors - research, the production of means of production and the sector of production of final products. In the research sector, as a result of using the human capital $H_{A}$ and concentrated in it and the existing stock of knowledge $A$, new knowledge is formed, which materializes in the form of new technologies. The gain of new knowledge is expressed by the formula:

$$
A=\delta H_{A} A
$$

Where $\delta$ - is the parameter of scientific productivity. The production sector does not have its own intellectual human capital, but pays the labor of scientists to create new technologies in the first sector. The fee for the use of a human capital unit in the research sector is calculated as follows:

$$
w_{H}=P_{A} \delta A,
$$

Where $P$ - is the price of new technology.

After the acquisition and development of a new technological idea, a second sector firm protects its monopolistic right to use it with a patent and arranges the release of appropriate means of production for third sector firms. For the production of one piece of equipment, the final product of the third sector is consumed. The means of production are not sold, but leased for rent $-P_{i}$.

In the third sector, on the basis of the available means of production, labor and human capital, output of consumer goods is provided. The production function is

$$
Y\left(H_{Y}, L, x\right)=H_{Y}^{\alpha} L^{\beta} \sum_{i=1}^{\infty} x_{i}^{1-\alpha-\beta},
$$

Where $\alpha$ and $\beta$ - technological parameters.

The change in the total capital of a three-sector system is determined by the formula

$$
K(t)=Y(t)-C(t)=\eta \sum_{i=1}^{\infty} x_{i}
$$


Where $C(t)$ - aggregated consumption function.

The manufacturers of the final products build their relations with the manufacturers of the means of production based on the objectives of maximizing profits (output minus the cost of equipment):

$$
H_{Y}^{\alpha} L^{\beta} \sum_{i=1}^{\infty} x_{i}^{1-\alpha-\beta}-\sum_{i=1}^{\infty} P_{i} x_{i} \rightarrow \max
$$

Hence, in the conditions of market equilibrium, the inverse function of demand for new technologies is

$$
P_{i}=(1-\alpha-\beta) H_{Y}^{\alpha} L^{\beta} x_{i}^{-\alpha-\beta}
$$

Firms of the second sector who pay for the creation of new technologies in the research sector determine the volume of output for the third sector, taking into account the maximization of their income with the deduction of variable costs

$$
\pi=\max _{x} P(x) x-r \eta x=\max _{x}(1-\alpha-\beta) H_{Y}^{\alpha} L^{\beta} x_{i}^{1-\alpha-\beta}-r \eta x,
$$

Where $r$ - the rate of interest on capital.

For any point in time, excess of income over marginal costs per unit of time should cover interest payments on the amount of investment in the development of a new technology.

$$
\pi(t)=r(t) P_{A} .
$$

For an equilibrium trajectory of balanced growth, the variables $\mathrm{A}, \mathrm{K}$, and $\mathrm{Y}$ increase exponentially with the same constant speed, and the value $g$ of $\mathrm{L}, H_{Y}$ and the average value are fixed.

$$
\bar{x}^{1-\alpha-\beta}=\frac{K}{\eta A}
$$

Then the expected growth rate is estimated as

$$
g=\delta H_{a}=\delta H-\gamma, \gamma=\frac{\alpha}{(1-\alpha-\beta)(\alpha+\beta)},
$$

Where $H$ - total human capital of the first and third sectors,

$g$ - constant, depending only on the technological parameters $\alpha$ and $\beta$.

The economic growth rate is inversely related to the bank interest rate and in direct proportion to the amount of human capital concentrated in the area of obtaining new knowledge.

Thus, the innovation sphere influences the national economy not only directly through new applied ideas and developments. Its existence is a necessary, but not a sufficient condition for economic growth, since it ensures the accumulation of human capital. Without encouraging the acquisition of new knowledge for the sake of knowledge as such, one can hardly count on the necessary practical benefits from science in the future. 
A publicly accessible educational environment will open up opportunities for a continuous process of learning and professional implementation for everyone. It will include, among other things, distance programs and individual learning paths. Processing and analysis of the results of the learning process, collected in a single array of Big data, will ensure the disclosure of the abilities of each student. The use of innovative technologies - gamification, VR / AR / MR, three-dimensional modeling and printing - will make the process of learning more informative, exciting and creative.

Digitizing all documents and materials of cultural and scientific value will help simplify access to social services, educational, scientific and cultural services, as well as diversify leisure opportunities. Providing schools with modern equipment and software necessary for implementing adaptive programs.

So, people, processes and technologies are the three sources of the successful initiative of a smart city. Cities should study their citizens and communities, be aware of the processes, business drivers, conduct policies and set goals in accordance with the needs of citizens. In this case, technologies can be used to meet the needs of citizens, improve the quality of life, and create real economic opportunities. This requires a holistic, unique approach that takes into account urban culture and long-term urban planning, as well as local norms.

\section{Conclusion}

According to the research, the implementation of the concept of "smart cities" requires solving the task of developing human resource potential from the standpoint of its bilateral assessment. The methodological aspects of the development of personnel potential, considered in this article, are based on the duality of the nature of the studied category in the digital economy. The duality of nature is revealed in the process of practical implementation of the development of human potential. A specialist is a producer of an innovative product and, at the same time, a consumer of new knowledge. A citizen of a "smart city" is a manufacturer of high-tech products and, at the same time, a resident of a "smart home" is its consumer. Each subject of economic activity is a source of information for "smart" urban systems and, accordingly, a consumer of technologies created using this information.

An analysis of the strengths and weaknesses of the digitalization of the urban economy confirmed its inevitability and necessity. The considered Romer's model indicates that today human capital is the basis of economic growth and technological changes are possible thanks to the purposeful activities of highly qualified specialists.

As applied to the main task of the research, enterprises, educational institutions and the state act as basic subjects of interaction. Taking into account the fact that the decision on the organization of partnerships with the university is made by the company, an analysis of the preferred options for the interaction under consideration has been conducted. It has been revealed that the majority of potential employers are oriented towards carrying out work experience, showing a much smaller interest in developing joint training courses and programs, and attracting students to work on joint projects. In this situation, measures to harmonize the process and results of training graduates of universities and the requirements of the labor market are particularly relevant.

A number of methods for the development of cooperation between enterprises and educational institutions, taking into account the duality of the nature of human resources, are highlighted, and the shortcomings of their use are noted.

In the process of research, the experience of specific universities and enterprises, including the Voronezh universities, on the organization of joint training of highly qualified specialists was reviewed. The article presents as examples the experience of an innovative 
approach to the organization of interaction between a university and enterprises based on the VSTU.

The interaction methods discussed in the article suggest a multi-aspect solution of the problem of raising the level of knowledge and skills of students and workers. Practical experience in the implementation of methods makes it possible to approach the solution of the problem consistently and purposefully.

\section{References}

1. V. Kupriyanovsky, N. Utkin, D. Nikolaev, D. Yartsev, D. Namiot, S. Sinyagov, International Journal of Open Information Technologies 4(7), 13-21 (2016)

2. V. Chichkanov, E. Chistova, A. Tyrsin, Economic and Social Changes: Facts, Trends, Forecast 11(5), 87-102 (2018)

3. T. Davydova, E. Zhutaeva, T. Dubrovskaya, IOP Conference Series: Earth and Environmental Science 90(1), A012168 (2017)

4. D. Cowan, P. Alencar, K. Young, B. Smale, R. Erb, F. McGarry, 2017 IEEE International Conference on Big Data (BIG DATA), 4058-4067 (2017)

5. D. Namiot, V. Kupriyanovsky, A. Samorodov, O. Karasev, D. Zamolodchikov, N. Fedorova, International Journal of Open Information Technologies 5(3), 56-71 (2017)

6. R. Smale, G. Spaargaren, B. van Velt, Building Research \& Information 47(5), 585597 (2019)

7. T. Averina, E. Avdeeva, O. Perevalova, MATEC Web of Conferences conference proceedings, 01121 (2018)

8. E. Avdeeva, T. Averina, L. Kochetova. E3S Web of Conferences, 03013 (2018)

9. A. Marengo, A. Pagano, L. Ladisa, 12th International Technology, Education and Development Conference (INTED), 2978-2983 (2018)

10. M. Khan, Proceedings 2016 Eighth Annual IEEE Green Technologies Conference (GREENTECH 2016), 107-111 (2016)

11. G. Astratova, N.A. Shklyaeva, Upravlenets-the Manager 9(1), 38-47 (2018)

12. P. Lago, C. Roncancio, C. Jimenez-Guarin, International Journal of Escience 91, 191205 (2019)

13. A. Al-Aiad, K. Alkhatib, M. Al-Ayyad, I. Hmeidi, International Journal of Healthcare Information Systems and Informatics 11(3), UNSP 3 (2016)

14. K. Tan, T. Logenthiran, W. Woo, R. Naayagi, Proceedings of the 2016 IEEE Region 10 Conference (TENCON), 1185-1189 (2016)

15. A. Alhamoud, P. Xu, F. Englert, P. Scholl, T. Nguyen, D. Bohnstedt, R. Steinmetz, 2015 IEEE International Conference on Pervasive Computing and Communication Workshops (PERCOM WORKSHOPS), 20-25 (2015)

16. C. Cong, X. G. Chen, Q. Yang, Proceedings of the 2016 3RD International Conference on Management, Education Technology and Sports Science (METSS 2016) 25, 64-69 (2016) 